Instructions for authors, subscriptions and further details:

http://qre.hipatiapress.com

\title{
El Diseño de Investigación Cualitativa, por Uwe Flick
}

Laura Fernández García ${ }^{1}$

1) Universidad de Oviedo, Spain.

Date of publication: October $28^{\text {th }}, 2016$

Edition period: June 2016 - October 2016

To cite this article: Fernández García, L. (2016). El diseño de Investigación Cualitativa [Book Review]. Qualitative Research in Education, 5(3), 332-334. doi:10.17583.qre.2016.2364

To link this article: http://dx.doi.org/10.17583.qre.2016.2364

\section{PLEASE SCROLL DOWN FOR ARTICLE}

The terms and conditions of use are related to the Open Journal System and to Creative Commons Attribution License (CC-BY). 


\section{Review I}

Flick, U. (2015). El diseño de Investigación Cualitativa. Madrid: Ediciones Morata. ISBN: 978-84-7112-807-2

El diseño de Investigación Cualitativa es el primer volumen de la Colección de Investigación Cualitativa dirigida por el autor Uwe Flick. Ésta obra ofrece una perspectiva amplia y general acerca de este tipo de investigación, de forma que la hace fácilmente comprensible para aquellos investigadores que se inician en éste campo. Por otro lado, esta obra también puede tener utilidad para aquellos investigadores experimentados que puedan necesitar de una guía que reúna todos los elementos y consideraciones a tener en cuenta para garantizar un diseño de investigación cualitativa de calidad. Además, en el caso de tener interés de ahondar en alguno de los aspectos recogidos, en la introducción se describe el contenido de cada uno de los volúmenes de la colección, facilitando así al lector la selección del aspecto sobre el que necesite tener un conocimiento en mayor profundidad. Adicionalmente, al final de cada capítulo se proponen diferentes lecturas que puedan aportar más información sobre el apartado tratado.

El primer capítulo se trata del más amplio. En él, el autor comienza por aclarar qué es la investigación cualitativa, haciendo además un repaso de la proliferación de este tipo de investigación a lo largo de la historia. Recalca de igual forma la necesidad de utilizar unos métodos idóneos para la temática estudiada, y cómo de esta forma en muchas ocasiones surgen nuevos métodos a partir de las necesidades surgidas en el proceso de investigación. Además, explica cómo la investigación cualitativa ha ido adquiriendo mayor relevancia en el ámbito académico. También se realiza una aclaración sobre la relación entre la calidad y la cantidad, considerando la necesidad de entender que ambas investigaciones no se excluyen, sino que existen casos en los que se pueden y se deben complementar. La última parte del capítulo está dedicado a cómo elegir diferentes perspectivas 
de investigación y desarrolla las teorías y áreas de conocimiento que sustentan éste tipo de investigación, así como los métodos y actitudes que se pueden utilizar.

A partir del capítulo dos y hasta el siete, el autor comienza a esbozar los diferentes aspectos a tener en cuenta a la hora de enfrentarnos a una investigación cualitativa. Por otro lado, también se molesta en explicar que hay ciertos mitos en torno a este tipo de investigación que deben de romperse, tales como que por definición este tipo de investigación no debe basarse en teorías ya existentes, o que debe investigar aspectos no indagados con anterioridad. Para Flick, precisamente debemos adoptar la posición contraria y basarnos en todas las teorías e investigaciones que se hayan podido desarrollar con anterioridad acerca de la temática elegida, ya que, aprovechando estas referencias como puntos de apoyo, lograremos una mayor contundencia en nuestra investigación. Habiendo aclarado el punto de partida, el autor nos guía en el desarrollo de los diferentes elementos: la necesidad de partir de la aclaración de la pregunta de investigación, la perspectiva que adoptaremos en su desarrollo y el proceso de selección de muestra. Es en el capítulo cuarto, en el que nos introduce al propio diseño de investigación, conociendo, entre otros aspectos, los diferentes tipos de diseños que podemos utilizar. Además, en este caso el autor utiliza el ejemplo de dos diseños para mostrar de forma más clara la aplicación práctica. Otros aspectos que no debemos olvidar son los desarrollados en los capítulos cinco, seis y siete, que son aquellos que le van a dar realismo y firmeza a nuestra investigación: los recursos que podemos necesitar sin dejar a un lado los obstáculos a los que nos tendremos que enfrentar, la importancia de las diferentes cuestiones relativas a la calidad a lo largo de la investigación y las implicaciones éticas y morales que se pueden dar a lo largo del proceso.

Es en la última parte del libro cuando el autor nos explica de una forma más específica los métodos que podemos utilizar, dividiéndolos en métodos para la recogida de datos verbales, etnográficos y visuales, cerrando esta fase con los métodos para el análisis de datos, presentando en primer caso enfoques más generales (codificación y categorización) y cerrando el capítulo con un análisis de datos más específico. Debido a la claridad con la que se presentan las conclusiones en el último capítulo, acerca de las cuestiones de diseño y la redacción de la propuesta, el lector se queda con la sensación de conocer de forma general todos los aspectos básicos a tener 
en cuenta a la hora de desarrollar una investigación de este tipo, volviendo a hacer referencia al resto de volúmenes de la colección para conocer más detalles.

A modo de conclusión, señalaremos que es un libro que debe ser considerado como una guía introductoria global a los métodos cualitativos, debido a la claridad con la que se desgranan los diferentes aspectos de la misma, haciéndolo así comprensible y accesible para los profesionales de las diferentes disciplinas dentro del campo de la investigación.

Laura Fernández García

Universidad de Oviedo fdezgarcilaura@gmail.com 